types and grades, who underwent the Sentinel Lymph Node by immunofluorescence Technique and/or systematic lymphadenectomy between June 2019 and March 2020 at the Fundación Jiménez Díaz University Hospital.

We used indocyanine green powder. We proceeded to dissolve it in 10 cubic centimeters of distilled water. After which, we injected $2 \mathrm{cc}$ of the prepared solution into the cervix at the 3 and 9 o'clock positions at a depth of $1 \mathrm{~cm}$.

Result(s)* Eighteen patients were included, analyzing a total of 26 sentinel nodes: 24 pelvic and 2 paraortic; and a total of 273 lymph nodes (sentinel and non-sentinel nodes): 83 right pelvic, 86 left pelvic and 104 paraortic. All nodes were negative for metastasis.

Global and bilateral detection rates were $77.78 \%$ and 50\% respectively. The Negative Predictive Value and sensitivity were $100 \%$. No significant difference in morbimortality was found between performing only Sentinel Lymph Node technique or systematic lymphadenectomy; but the association with quality of life was significant, with better results for those who only underwent the sentinel lymph node technique versus systematic lymphadenectomy ( $0 \%$ vs $77 \%)$.

However, we observed at the beginning of the study, bilateral detection was very limited. This could be due to a failure in the tracer injection technique in our first 10 patients. Because since from the standardization of the technique we obtained a considerable improvement in bilateral detection; $87.5 \%$ (before technical standardization 20\%). This supports the theory that technique is the most important factor in detection (Rossi, 2019).

Conclusion* The global and bilateral detection rates of the Sentinel Lymph Node Technique by immunofluorescence were $77.78 \%$ and $50 \%$ respectively, obtaining a Negative Predictive Value and Sensitivity of $100 \%$. Sentinel Node Biopsy is a valid technique to predict lymphatic affectation in early endometrial cancer, with lower morbimortality than systematic lymphadenectomy

\section{ADOPTION OF MINIMALLY INVASIVE SURGERY AND DECREASE IN SURGICAL MORBIDITY FOR ENDOMETRIAL CANCER IN THE CANARY ISLANDS}

${ }^{1} \mathrm{~V}$ Benito*, ${ }^{1} \mathrm{~A}$ Lubrano, ${ }^{2} \mathrm{~L}$ León, ${ }^{3} \mathrm{~F}$ Molano, ${ }^{4} \mathrm{~B}$ Pinar. ${ }^{1}$ Hospital Materno Infantil, Gynecology and Obstetrics, Las Palmas de Gran Canaria, Spain; ${ }^{2}$ Hospital Materno Infantil, Pathology, Las Palmas de Gran Canaria, Spain; ${ }^{3}$ Hospital Insular, Medical Oncology, Las Palmas de Gran Canaria, Spain; ${ }^{4}$ University Hospital of Gran Canaria Dr. Negrin, Radiation Oncology, Las Palmas de Gran Canaria, Spain

\subsection{6/ijgc-2021-ESGO.233}

Introduction/Background* After minimally invasive surgery gained popularity in gynecology oncology, laparoscopic operations became widespread among oncologic operations, however more studies evaluating safety and morbidity of laparoscopic surgery during the learning period of laparoscopy are needed.

Methodology A prospective study of 895 consecutive patients diagnosed with clinical stage I endometrial cancer managed between January 2005 and December 2016 in a Department of Gynaecology Oncology in a tertiary center in the Canary Islands. The open surgery group was compared to the minimally invasive surgery group over these years. Both groups were compared for epidemiological and clinical characteristics, surgery outcomes, pathologic findings, hospital stay and intraoperative and postoperative complications.
Result(s)* There were no differences between both groups in terms of median age, percentage of previous laparotomies and median BMI. Median operating time was longer for the laparoscopic group, although the observed differences were not significant. The estimated blood loss was significantly less for the laparoscopic group. There were no differences in intraoperative complications although postoperative adverse events were significant lower in the laparoscopic group. Hospital stay was significantly longer in the laparotomic arm. There were no significant differences in the percentage of readmissions, reoperations and death related to treatment between both groups.

Conclusion* Laparoscopic surgery in early-stage endometrial cancer is a safe and effective surgical approach applicable in any center with appropriate training. It is possible to change drastically the surgical management of endometrial cancer thus reducing significantly morbidity: less blood loss, less postoperative adverse events and shorter duration of hospital stays, compared to laparotomic surgery.

\section{PREVALENCE OF ENDOMETRIAL CARCINOMA IN WOMEN WITH MYOMA UTERI ASSOCIATED ABNORMAL UTERINE BLEEDING (AUB) IN A TERTIARY GOVERNMENT HOSPITAL}

JL Tanchuling. East Avenue Medical Center, Obstetrics and Gynecology, Quezon , Philippines

\subsection{6/ijgc-2021-ESG0.234}

Introduction/Background* Myomas are the most common benign neoplasm of the female reproductive organs. They most commonly cause abnormal uterine bleeding (AUB) which is also manifestation of endometrial carcinoma. These two conditions can co-exist due to their sensitivity to estrogenic stimulation. This association, as reported in few reported articles, was also reproduced in this paper.

Methodology The study was a cross sectional retrospective in nature, which involves patients diagnosed with any kind of uterine fibroids presenting with abnormal uterine bleeding that

Abstract 1158 Table 1 Factors associated with endometrial carcinoma among myoma uteri patients

\begin{tabular}{lllll}
\hline & Crude & & Adjusted & \\
\cline { 2 - 5 } & OR $(95 \% \mathrm{Cl})$ & $p$ & OR $(95 \% \mathrm{Cl})$ & $p$ \\
\hline Age & $1.036(1.02$ to 1.06$)$ & 0.001 & $1.058(1.01$ to 1.10$)$ & 0.010 \\
BMI & & & & \\
$18.5-24.9$ & Reference & - & Reference & - \\
$<18.5$ & $0.260(0.03$ to 2.15$)$ & 0.212 & $0.719(0.07$ to 7.09$)$ & 0.777 \\
$25.0-29.9$ & $1.396(0.81$ to 2.40$)$ & 0.226 & $0.986(0.54$ to 1.81$)$ & 0.963 \\
$\geq 30.0$ & $0.520(0.06$ to 4.81$)$ & 0.564 & $0.927(0.08$ to 10.50$)$ & 0.951 \\
Gravidity & $1.123(0.99$ to 1.27$)$ & 0.062 & $1.173(0.70$ to 1.96$)$ & 0.543 \\
Parity & $1.124(0.99$ to 1.28$)$ & 0.078 & $0.890(0.53$ to 1.51$)$ & 0.666 \\
Age of menopause & $2.721(1.10$ to 6.75$)$ & 0.031 & $2.164(0.66$ to 7.04$)$ & 0.200 \\
Menstrual irregularity & $0.856(0.33$ to 2.19$)$ & 0.745 & $0.911(0.32$ to 2.59$)$ & 0.861 \\
Intermenstrual & $0.239(0.07$ to 0.83$)$ & 0.024 & $0.133(0.04$ to 0.50$)$ & 0.003 \\
bleeding & & & & \\
Comorbidities & & & & \\
Hypertension & $2.220(1.25$ to 3.96$)$ & 0.007 & $1.176(0.53$ to 1.87$)$ & 0.691 \\
Diabetes & $1.107(0.62$ to 1.97$)$ & 0.731 & $0.893(0.43$ to 1.87$)$ & 0.764 \\
\hline & & & & \\
\hline
\end{tabular}


were subjected to hysterectomy at a tertiary hospital from January 2015 - October 2019. A total of 284 recorded, eligible post hysterectomy cases were included.

Result(s)* This retrospective cohort study shows that the prevalence of endometrial carcinoma among Filipino women with myoma uteri associated AUB which equates to $11 \%(n=31)$.
Types $2 \& 3$ fibroid were associated with endometrial carcinoma,and were found to have the highest incidence of $68.75 \%$ and $48.89 \%$. The higher the age, and presence of intermenstrual bleeding are strongly associated with the development of endometrial carcinoma among patients with myoma uteri each with a $\mathrm{p}$ value of $<0.05$.

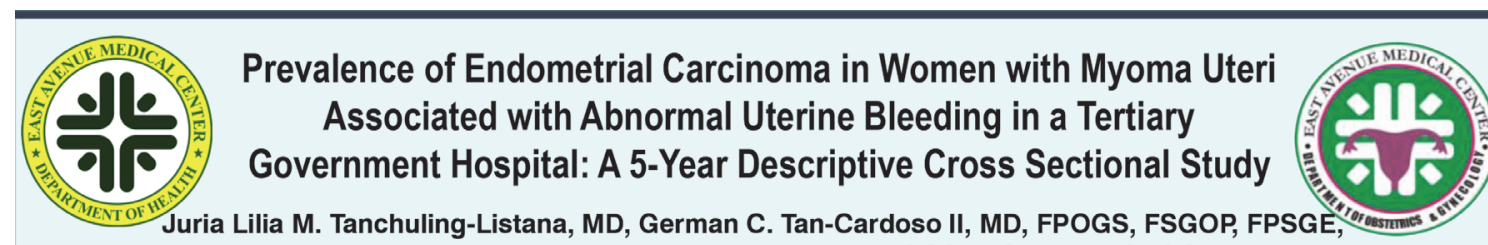
Brenda Bernadette P. Bautista-Zamora, MD, FPOGS,FPSMFM,FPSUOG

East Avenue Medical Center

\section{INTRODUCTION}

Myomas are the most common benign neoplasm of the female reproductive organs. They most commonly cause abnormal uterine bleeding (AUB) which is also manifestation of endometrial carcinoma. These two conditions can co-exist due to their sensitivity to estrogenic stimulation. This association, as reported in few reported articles, was also reproduced in this paper.

\section{OBJECTIVES}

This study determined the prevalence of endometrial carcinoma in patients with myoma uteri manifesting with AUB who underwent total hysterectomy among Filipino women. This association may serve to guide clinicians in the management when these 2 conditions co-exist.

\section{METHODS}

The study was cross-sectional retrospective in nature, which involves patients diagnosed with any kind of uterine fibroids presenting with AUB that were subjected to hysterectomy at a tertiary hospital from January 2015 to October 2019. A total of 284 recorded, eligible post-hysterectomy cases were included.

\section{RESULTS}

The observed prevalence of endometrial carcinoma among Filipino women with myoma uteri associated AUB is $11 \%(n=31)$. Types 2 and 3 fibroids were associated with endometrial carcinoma, and were found to have the highest incidence of $68.75 \%$ and $48.89 \%$, respectively. Age of menopause (OR 2.721, $96 \% \mathrm{Cl}$ $1.10-6.75, \quad p=0.031)$, presence of intermenstrual bleeding (OR 0.239, $95 \% \mathrm{Cl} 0.07-0.83, \mathrm{p}=0.024)$ and hypertension (OR $2.220,95 \% \mathrm{Cl} 1.25-$ 3.96, $p=0.007$ ) are strongly associated with the development of endometrial carcinoma among patients with myoma uteri.

\section{CONCLUSION}

Evaluation of endometrium in patients with increasing postmenopausal age, hypertension and intermenstrual bleeding before performing hysterectomy for patients with myoma uteri associated bleeding is a must to avoid inadequate surgical treatment. 
Conclusion* Evaluation of endometrium in patients with increasing post menopausal age, hypertension and intermenstrual bleeding before performing hysterectomy for patients with myoma uteri associated bleeding is a must to avoid inadequate surgical treatment

\section{Fertility pregnancy}

\section{COMPREHENSIVE GENOME-WIDE ANALYSIS OF NON- INVASIVE TEST DATA ALLOWS ACCURATE CANCER PREDICTION: A RETROSPECTIVE ANALYSIS OF OVER 85.000 PREGNANCIES}

${ }^{1} \mathrm{~L}$ Lenaerts ${ }^{*},{ }^{2} \mathrm{~N}$ Brison, ${ }^{1} \mathrm{C}$ Maggen, ${ }^{2} \mathrm{~L}$ Vancoillie, ${ }^{3} \mathrm{H}$ Che, ${ }^{4} \mathrm{P}$ Vandenberghe, ${ }^{4} \mathrm{D}$ Dierickx ${ }^{2} \mathrm{~L}$ Michaux, ${ }^{2} \mathrm{~B}$ Dewaele, ${ }^{5} \mathrm{P}$ Neven, ${ }^{6} \mathrm{G}$ Floris, ${ }^{3} \mathrm{~T}$ Jatsenko, ${ }^{5} \mathrm{~K}$ Van Calsteren, ${ }^{7} \mathrm{~V}$ Vandecaveye, ${ }^{8} \mathrm{~L}$ Dehaspe, ${ }^{2} \mathrm{~K}$ Devriendt, ${ }^{2} \mathrm{E}$ Legius, ${ }^{2} \mathrm{~K}$ Van Den Bogaert, ${ }^{3} \mathrm{~J}$ Vermeesch, ${ }^{1} \mathrm{~F}$ Amant. ${ }^{1}$ Catholic University Leuven, Oncology, Belgium; ${ }^{2}$ University Hospitals Leuven, Center for Human Genetics, Belgium: ${ }^{3}$ Catholic University Leuven, Human Genetics, Belgium; ${ }^{4}$ University Hospitals Leuven, Hematology, Belgium; ${ }^{5}$ University Hospitals Leuven, Gynaecology and Obstetrics; ${ }^{6}$ University Hospitals Leuven, Pathology, Belgium; ' University Hospitals Leuven, Radiology, Belgium; ${ }^{8}$ Catholic University Leuven, Genomics Core facility, Belgium

\subsection{6/ijgc-2021-ESGO.235}

Introduction/Background* Implausible false positive results in non-invasive prenatal testing (NIPT) have been occasionally associated with the detection of occult maternal malignancies. Hence, there is a need for approaches allowing accurate prediction of whether the NIPT result is pointing to an underlying malignancy, as well as for organized programs ensuring efficient downstream clinical management of these cases.

Methodology Using a large data set of 88,294 NIPT performed in our University Hospital Leuven, we retrospectively evaluated the positive predictive value (PPV) of our NIPT approach for cancer detection. In this approach, whole-genome cell-free DNA (cfDNA) data from NIPT were scrutinized for the presence of (sub)chromosomal copy number alterations (CNAs) predictive for a malignancy, using an unbiased NIPT analysis pipeline coined GIPSeq. For suspected cases, the presence of a maternal cancer was evaluated via subsequent multidisciplinary clinical follow-up examinations. The cancer-specificity of the identified CNAs in cfDNA was assessed through genetic analyses of a tumour biopsy.
Result(s)* Fifteen women without a cancer history were identified with a GIPSeq result suggestive of a malignant process. Their cfDNA profiles showed either genome-wide aberrations or a single trisomy 8. Upon clinical examinations, a solid or hematological cancer was identified in 4 and 7 cases, respectively. Three women were identified as having a clonal mosaicism. For one case no underlying condition was found. These numbers add to a PPV of $73 \%$. Based on this experience, a novel multidisciplinary care path for efficient clinical management of these cases was presented.

Conclusion* The here presented approach for analysing NIPT results has an unparalleled high PPV, yet unknown sensitivity, for detecting asymptomatic malignancies upon routine NIPT. Given the complexity of diagnosing a pregnant woman with cancer, clinical follow-up should occur in a well-designed multidisciplinary setting, such as via the novel care model that we presented here.

These findings have now been accepted for publication in eClinicalMedicine (online journal of The Lancet group), showing the importance of these data.

\section{FERTILITY-SPARING TREATMENT IN SEROUS BORDERLINE OVARIAN TUMORSWITH EXTRA-OVARIAN INVASIVE IMPLANTS. AN ANALYSIS FROM THE MITO14 STUDY DATABASE}

${ }^{1} \mathrm{~F}$ Falcone* ${ }^{*}{ }^{2} \mathrm{M}$ Malzoni, ${ }^{3} \mathrm{G}$ Cormio, ${ }^{4} \mathrm{AM}$ Perrone, ${ }^{5} \mathrm{MG}$ Ferrandina, ${ }^{6} \mathrm{~L}$ Frigerio, ${ }^{7} \mathrm{VDI}$ Donato, ${ }^{8} \mathrm{~F}$ Raspagliesi, ${ }^{9} \mathrm{~N}$ Losito, ${ }^{1} \mathrm{~S}$ Greggi. ${ }^{1}$ Istituto Nazionale Tumori, IRCSS, 'Fondazione G. Pascale', Department of Gynecologic Oncology, Naples, Italy; ${ }^{2}$ Center for Advanced Endoscopic Gynecologic Surgery, Endoscopica Malzoni, Avellino, Italy; ${ }^{3}$ University of Bari 'Aldo Moro', Department of Biomedical Sciences and Human Oncology, Unit of Obstetrics and Gynecology, Bari, Italy; ${ }^{4}$ RCCS Azienda Ospedaliero-Universitaria di Bologna, Division of Oncologic Gynecology, Bologna, Italy; ${ }^{5}$ Fondazione Policlinico Universitario A. Gemelli, IRCCS, Department of Woman and Child Health and Public Health, Rome, Italy ${ }^{6}$ ASST Papa Giovanni XXIII, Bergamo, Obstetrics and Gynecology Department, Bergamo, Italy: 'Umberto I, 'Sapienza' University of Rome, Department of Maternal and Child Health and Urological Sciences, Rome, Italy; ${ }^{8}$ Fondazione IRCCS Istituto Nazionale dei Tumori, Milan, Gynecologic Oncology, Milan, Italy; ${ }^{9}$ Istituto Nazionale Tumori, IRCSS, 'Fondazione G. Pascale', Surgical Pathology Unit, Naples, Italy

\subsection{6/ijgc-2021-ESGO.236}

Introduction/Background* Only 10-15\% of serous borderline ovarian tumors (SBOT) have extra-ovarian invasive implants, and conservative treatments have been rarely reported. The MITO14 is a multi-institutional retrospective study conducted

Abstract 94 Table 1 Patient, tumor, and treatment related characteristics

\begin{tabular}{|c|c|c|c|c|c|c|c|c|c|c|c|}
\hline Case\# & $\begin{array}{l}\text { Age } \\
\text { (yr) }\end{array}$ & \begin{tabular}{|c|}
$\mathrm{BMI}$ \\
$(\mathrm{kg} / \mathrm{m} 2)$
\end{tabular} & $\begin{array}{l}\text { Previous } \\
\text { pregnancy }\end{array}$ & $\begin{array}{l}\text { Preoperative } \\
\text { serum CA125 } \\
\text { levels }(\mathrm{U} / \mathrm{mL})\end{array}$ & $\begin{array}{c}\text { Bilateral } \\
\text { ovarian } \\
\text { involvement }\end{array}$ & $\begin{array}{c}\text { Peritoneal } \\
\text { cancer index } \\
\text { (no.) }\end{array}$ & $\begin{array}{l}\text { Surgical } \\
\text { approach }\end{array}$ & $\begin{array}{l}\text { Completeness of } \\
\text { cytoreduction, } \\
\text { (score)* }\end{array}$ & $\begin{array}{c}\text { Surgical management } \\
\text { of ovarian lesion(s) }\end{array}$ & $\begin{array}{l}\text { FIGO } \\
\text { stage }\end{array}$ & $\begin{array}{c}\text { Adjuvant } \\
\text { chemotherapy } \\
\text { after surgery }\end{array}$ \\
\hline 1 & 34 & 22.7 & - & 406 & no & 5 & open & 0 & U so & IIIB & no \\
\hline 2 & 36 & 23.2 & 1 NFTD & 210 & yes & 6 & laparoscopy & 0 & SO + contralateral Cys & IIIB & no \\
\hline 3 & 19 & 27.8 & - & 381 & no & 3 & laparoscopy & 0 & U Cys & IIB & no \\
\hline 4 & 33 & 25,0 & - & 100 & yes & 3 & open & 1 & B Cys & IIB & yes \\
\hline 5 & 28 & 20.2 & - & 180 & no & 5 & open & 2 & U Cys & IIIB & yes \\
\hline 6 & 31 & 26.5 & 1 NFTD & 46 & yes & 6 & laparoscopy & 0 & B Cys & IIIB & no \\
\hline 7 & 23 & 24.1 & - & 80 & no & 4 & open & 0 & U so & IIIB & yes \\
\hline 8 & 26 & 15.7 & - & 2616 & yes & 12 & open & 2 & So + contralateral Cys & IIIB & yes \\
\hline 9 & 33 & 20,4 & 1 NFTD & 60 & no & 8 & open & 0 & U so & IIIB & no \\
\hline 10 & 27 & 22.4 & - & 289 & no & 4 & open & 0 & U so & IIIB & yes \\
\hline 11 & 43 & 21.5 & - & 41 & no & 4 & open & 0 & U So & IIIB & no \\
\hline 12 & 36 & 26.3 & - & 957 & yes & 2 & open & 0 & So + contralateral Cys & IIB & no \\
\hline 13 & 30 & 22.3 & 1 SFTM & 889 & yes & 10 & open & 1 & SO + contralateral Cys & IIIB & yes \\
\hline
\end{tabular}

B, bilateral; Cys, cystectomy; NFTD, normal full-term delivery; SFTM, sponta neous first-trimester miscarriage; so, salpingo-oophorectomy; $U$, unilateral. 